\title{
Sociodemographic, Psychological and Adolescent- related Factors Associated with Alcohol Consumption among School-going Adolescents
}

\author{
Nurulhuda Mat Hassan*, Nizatul Nurain Mazubir, Siti Norazlina Juhari, \\ Mohd Faeiz Pauzi and Norwati Daud \\ Faculty of Medicine, Universiti Sultan Zainal Abidin, 20400, Kuala Terenggan, Terengganu, \\ Malaysia; nurulhudamh@unisza.edu.my,nizatulnurain@gmail.com, faiezpauzi@unisza.edu.my, \\ azlinajuhari@unisza.edu.my,norwatidaud@unisza.edu.my
}

\begin{abstract}
Drinking alcohol is a potential addictive behavior causing significant morbidity and mortality that can be prevented in adolescents. Psychological and other significant factors related to adolescent drinking need to be identified to design a more population-specific screening and intervention to prevent alcohol use among adolescents. This study aims to find the prevalence of alcohol consumption and the psychological factors associated with it among school-going adolescents in Terengganu, Malaysia. This cross-sectional study was conducted among 732 school adolescents aged between 13 and 18 years from 12 secondary schools in Terengganu, Malaysia. Cluster sampling was applied to choose the schools and classes were selected by computerized simple random sampling. A validated questionnaire adapted from Global Health School Survey (GSHS) was used and psychological aspects were assessed using the validated Malay version of Strength and Difficulty Questionnaire (SDQ). Data were analyzed using SPSS ver. 25, using multiple logistic regressions for dependent variable of alcohol drinking. Alcohol consumption was defined as any alcohol beverage intake of more than a few sips. Prevalence of alcohol consumption was 5.2\% (95\% CI: 3.7, 7.1). Peer problems score was significantly associated with ever drinking of alcohol ( $\mathrm{p}=0.046$, OR: 1.39, 95\% CI: 1.01, 1.93); together with other significantly associated factors; namely younger age ( $p<0.001$, OR: $0.46,95 \%$ CI: $0.31,0.67)$, race $(p=0.002$, OR: $47.92, \mathrm{CI}=19.42,118.26)$, having single parents $(\mathrm{p}=0.021, \mathrm{OR}: 4.35, \mathrm{CI}=1.25,15.19)$ and being with drunk friends $(\mathrm{p}=0.001, \mathrm{OR}: 1.52, \mathrm{CI}=1.81,1.96)$. The study findings emphasized the significance of peers-related factors with consumption of alcohol among adolescents; either having peer problems or being around drunk friends, other than younger age, race and having divorced or single parent. Screening and intervening via peer problems may be a way to prevent onset of alcohol addiction in adolescents and thus preventing the future morbidity and mortality associated with it.
\end{abstract}

Keywords: Alcohol, Adolescents, Peer Problems, SDQ

\section{Introduction}

Alcohol drinking is considered a hazardous act to health, which are important to be prevented in adolescents. Epidemiological data showed that alcohol intake is a major risk factor for non-communicable diseases and death due to injury ${ }^{1}$. Malaysian data showed that $11.8 \%$ or one in 10 Malaysian adults are current drinkers. Of these, $45.8 \%$ or one in two drinkers binge drink with 6 or more standard drinks in a sitting at least once a week. This puts

*Author for correspondence 
them at risk for road traffic accidents, making injuries due to the road traffic accidents the biggest cause of death for those who consume alcohol (up to 17.6\%), followed by liver cirrhosis and cancer ${ }^{2}$. This is tragic as the lives lost during accidents are of not only the drinker's, but also innocent incidental accident victims.

As for any substances, a significant proportion of alcoholics start experimenting at an early age. Adolescents, a group with age-span from 10 years of age to 19 years, are vulnerable to trying all types of substances. During the adolescent phase, the frontal cortex responsible for making sound decisions is still developing, while parts of the brain processing feelings of rewards are more matured. This condition makes them vulnerable to unpremeditated decision-making such as trying drugs or drinking alcohol due to curiosity and social pressure. This may affect their future health, as the risks to be among those addicted to substances are highest among the ones who start during adolescence ${ }^{3}$. In the United States, as high as $70 \%$ of 18 years old high school students have tried alcohol ${ }^{4}$, while studies done in Malaysia showed that $19.3 \%$ of adolescent have tried alcohol ${ }^{5}$.

The difference in the prevalence of alcohol consumption between countries highlights the influence of the sociocultural and religious of alcohol use. The context of alcohol use varies among different countries due to culture, policies and regional variations ${ }^{6}$. Therefore, in a country where majority of the population are Muslims or Buddhist, the influencing factors for consumption of alcohol may be different compared to other countries due to the religious restriction in alcohol use. Moreover, majority of the epidemiological studies regarding adolescent alcohol consumption focus mainly on sociodemographic factors such as age and gender; and association with high risk behavior 6 . Although many epidemiological studies have been done to delineate the associated factors of alcohol intake among adolescents, few studies have highlighted the psychological aspects associated with it. Finding out the contributing factors for adolescents to try alcohol in adolescents in a local population would help to identify potential preventive measures that can be done to curb this hazardous act in the particular population. Psychological factors and adolescent-related factors are indeed one of the factors that need further evaluation which are usually lacking in large-scale epidemiological studies.

Furthermore, adolescents rarely offer information regarding intake of substances such as alcohol. Identifying the psychological attributes of adolescents who tend to try alcohol may help in target screening and intervention. Therefore, this study investigates the prevalence of ever drinking of alcohol and the association between alcohol consumption with sociodemographic, psychological and adolescent-related factors among school-going adolescents in Terengganu, Malaysia. Thus, this study provides additional information regarding some modifiable factors that can be targeted for alcohol drinking prevention programmer in adolescents, other than the latest prevalence among adolescents in Terengganu, Malaysia.

\section{Methods}

\subsection{Study Design and Participants}

This cross-sectional study was done from December 2018 to September 2019 in Terengganu state, Malaysia. Approval to conduct the research was obtained from Ministry of Education Malaysia, Terengganu Department of Education, and the school authorities involved. Ethical approval was obtained from Universiti Sultan Zainal Abidin Human Research Ethics Committee (UHREC) (UniSZA/UHREC/2019/104).

The sample size of 720 was calculated using the following single proportion formula to determine the prevalence of drinking among school-going adolescent:

$\mathrm{n}=(\mathrm{Z} / \Delta)^{2} \mathrm{P}(1-\mathrm{P})$

$\mathrm{n}=$ Minimum required sample size

$\mathrm{Z}=1.96(95 \% \mathrm{CI}) \mathrm{D}=$ Precision $=0.05$

$\mathrm{P}=$ Prevalence of drinking alcohol among school-going adolescence $=19.3 \%^{5}$

$\mathrm{n}=(\mathrm{Z} / \Delta)^{2} \mathrm{P}(1-\mathrm{P})=(1.96 / 0.05)^{2} 0.19(1-0.19)$

$\mathrm{n} \approx 240$

Considering effect of cluster sampling, the sample size was doubled and to cover the missing data and non-response another $50 \%$ was added; making the total required subjects were $n=720$.

Inclusion criteria were students aged 13 to 18 years who can read and write as they have to answer the questionnaires themselves. Exclusion criteria were those who could not understand Malay language. The participants were recruited from twelve selected secondary schools in Terengganu, Malaysia. There are 151 government funded national secondary schools and 15 private schools in the state. Cluster sampling was done 
to select a total of eleven public schools and one private school. The schools were randomly selected from a list of secondary schools from Terengganu state, Malaysia for both cluster of public and private schools. A pre-visit was done to each school to brief the Principles of the schools regarding the study and distribute the research information to selected classes of Form One, Two and Four students. Form Six (lower six) was also included in one school. A total of 36 classes were included in the study. The classes were selected using computerized simple random sampling based on a list of classes provided by school administration offices before the pre-visit. All the students who fulfilled the inclusion and exclusion criteria in the selected classes were given research information sheets together with the study consent forms to be brought back and signed by their parents. During the data collection visit, self-administered questionnaires were distributed to students whom their parents consented.

\subsection{Tools}

A self-administered questionnaire in Malay language was used to collect data and was completed by the participants in their classrooms with the assistance of the researchers. The questionnaire consisted of portions of the Global School-based student Health Survey (GSHS) and the Strength and Difficulties Questionnaire (SDQ).

The GSHS questionnaire is a self-administered questionnaire to obtain data on young people's health behavior and protective factors related to the leading causes of morbidity and mortality among children and adults worldwide. It was a measure used in the Global Student Health Survey, which is a collaborative surveillance project designed to measure and assess the behavioural risk factors and protective factors in $10 \mathrm{key}$ areas among young people aged 13 to 17 years $^{7,8}$. This study used the questionnaire part which has screened for alcohol use. Ever alcohol was defined as any alcoholic beverage intake other than a few sips in the respondent's lifetime.

Additional adolescent-related risk factors were elicited via five statements which were carefully selected after extensive literature review, with scale of 1 to 10 were given. The statements area as follows: 'I am frequently with friends who get drunk', 'I frequently go out spending time loitering with friends', 'I usually go out without my parent's knowledge,' 'I do illegal motorcycle activities with my friends' and 'I always play truant'. These questions were rated from 1 (strongly disagree) to 10 (strongly agree). A pilot study was done to test this part of questionnaire with 50 respondents with a resultant Cronbach alpha of 0.82 .

Psychological aspects were evaluated using the Malay self-rated SDQ. The SDQ is a widely used behavioral screening tool ${ }^{8,9}$, developed by Goodman and colleagues as an open access screening tool, validated in multiple languages. It has 25 items that give rise to five subscales of five items each; which are Prosocial behaviour, Peer Problem, Emotional Problem, Conduct Problem and Hyperactivity scales. For each of the 5 scales the score can range from 0 to 10 . The SDQ is generally considered to be an instrument with good psychometric properties and the construct validity has been supported in the literature ${ }^{10-12}$. The Malay Self-report SDQ version has been validated with reliable internal consistency, a Cronbach's alpha coefficient of $0.70^{13}$. The total score of each subscales were taken as continuous variable and each subscale were taken as separate individual variable for the data analysis.

\subsection{Data Analysis}

Data from the questionnaires were entered to SPSS version 25. Data was then checked for completeness. Those with any missing data were excluded, leaving completed ones for analysis. Descriptive statistics was done using means and standard deviations for continuous data and frequencies ( $\mathrm{n}$ ) and percentages (\%) for categorical data. Simple and Multiple Logistic Regression was used to determine the associated factors for taking alcohol. Independent variables analyzed were age, gender, household income, parental marital status, presence of family members taking alcohol, adolescent-related factors and SDQ scores for all the subscales. For data analysis in the multivariate analysis, variables which had $\mathrm{p} \leq 0.25$ in the bivariate analysis were included; those with $\mathrm{p}<0.05$ with CI not including 1 remained in the final model.

\section{Results}

Response rate was $94.6 \%$ as a total of 732 adolescents out of 774 completed the questionnaire. However, one response was excluded due to missing data; leaving 731 analyzed.

Descriptive analysis is presented in Table 1 . Majority of the respondents were Malay (93.4\%) and female (54.3\%). Prevalence of ever taking alcohol drinks is 5.2\% $(95 \%$ CI $3.7,7.1)$. 
Table 2 shows the psychological aspects and adolescentrelated risk factors among respondents. The only significant subscale in SDQ using univariate analysis is peer problems, while two adolescent-related factors were found to be significant.

Table 3 shows the associated factors of smoking by simple and multiple logistic regression models. Younger age increases the odds for alcohol taking by $53 \%$ with 1 -year decrease in age. A race other than Malay is at 47.92 times more likely to have drank alcohol. Having separated, divorced or widowed parents increases the odds for trying of alcoholic drinks by 4.35 times. Adolescents who had a higher 1-point score in frequency of being around drunk friends had an increase of 1.52 times higher odds to try alcoholic drinks. Finally, peer problems increase the odds for trying alcohol by 1.39 times with one score increase in peer problems SDQ subscale.

Multicollinearity and interaction term were checked and not found. Classification table (overall correctly classified percentage $=97.2 \%$, which is $>70 \%$, Hosmer and Lemeshow test and area under ROC curve were applied to check the model fitness.

\section{Discussion}

Preventative science suggests that negative health outcomes, including those resulting from substance abuse, can be prevented by reducing risk factors and enhancing protective factors ${ }^{14}$. Therefore, the National Institute of Drug Abuse (NIDA) emphasizes the strategy of targeting modifiable risk factors and enhancing protective factors through family, school and community prevention programs ${ }^{3}$. Thus, this study provided additional information regarding some modifiable factors that can be targeted for alcohol drinking prevention programmes in adolescents, other than the latest prevalence.

The prevalence of ever drinking of alcohol in this study was $5.2 \%$, which is lower than the previous national prevalence of $18.9 \%$ in $2017^{2}$. However, the study population's state prevalence was shown to be relatively low in the national study with a state prevalence of $6.3 \%$. This lower prevalence may result from the overt predominance of Malay population (93.7\%) compared to the national survey, where the composition of Malay adolescents was $69.8 \%$. In Malaysia, Malays are generally of the Islamic religion whereby alcohol consumption is prohibited ${ }^{15}$. Furthermore, the state of our study location

Table 1. Prevalence of lifetime taking of alcohol among respondents according to sociodemographic characteristic

\begin{tabular}{|c|c|c|c|c|c|}
\hline & & Mean $(\mathrm{CI})$ & $\mathrm{n}(\%)$ & Prevalence of alcohol taking (CI) & $\begin{array}{l}\text { Mean in Alcohol } \\
\text { taking Group (CI) }\end{array}$ \\
\hline Age & & $14.7(14.60,14.8$ & & & $13.8(13.31,14.22)$ \\
\hline \multirow{4}{*}{ Race } & Malay & & $682(93.4)$ & $1.5(3.7,7.1)$ & \\
\hline & Chinese & & $45(2.2)$ & $62.2(46.5,76.2)$ & \\
\hline & Indian & & $2(<0.1)$ & 0 & \\
\hline & Others & & $1(<0.1)$ & 0 & \\
\hline \multirow[t]{2}{*}{ Gender } & Female & & $397(54.3)$ & $5.3(3.3,8.0)$ & \\
\hline & Male & & $334(45.4)$ & $5.1(3.0,8.0)$ & \\
\hline \multirow[t]{2}{*}{ Parental Status } & Married & & $666(91.2)$ & $5(4.4,6.9)$ & \\
\hline & $\begin{array}{c}\text { Divorced/Widowed/ } \\
\text { Separated }\end{array}$ & & $64(8.8)$ & $7.8(2.6,17.3)$ & \\
\hline \multirow[t]{2}{*}{ Household Income } & Less than RM3000 & & $438(61)$ & $2.7 \%(1.4,4.7)$ & \\
\hline & RM3000 and more & & $280(39)$ & $8.2 \%(5.3,12.1)$ & \\
\hline \multirow[t]{2}{*}{ Family taking alcohol } & Absent & & $639(95.1)$ & $2.5(1.4,4)$ & \\
\hline & Present & & $36(4.9)$ & $58.3(40.8,75.5)$ & \\
\hline
\end{tabular}


Table 2. Psychological aspects and adolescent-related risk factors among respondents

\begin{tabular}{cccc}
\hline $\begin{array}{c}\text { Psychological aspects based on SDQ } \\
\text { Subscale }\end{array}$ & Mean score(CI) & $\begin{array}{c}\text { Mean score(CI) for No } \\
\text { Alcohol }\end{array}$ & $\begin{array}{c}\text { Means score (CI) for alcohol } \\
\text { drinking }\end{array}$ \\
\hline Peer Problem & $3.97(3.87,4.08)$ & $3.94(3.84,4.45)$ & $4.55(4.14,4.96)$ \\
\hline Emotional Problem & $3.70(3.56,3.85)$ & $3.69(3.54,3.84)$ & $3.920(3.29,4.55)$ \\
\hline Hyperactivity & $3.98(3.85,4.11)$ & $3.96(3.83,4.10)$ & $4.24(3.64,4.84)$ \\
\hline Conduct Disorder & $2.50(2.39,2.62)$ & $2.49(2.37,2.61)$ & $2.79(2.27,3.31)$ \\
\hline Prosocial behaviour & $7.06(6.93,7.20)$ & $7.07(6.93,7.21)$ & $6.92(6.27,7.57)$ \\
\hline Adolescent-related risk factors & & & 0.487 \\
\hline Friends drunk & $1.18(1.10,1.25)$ & $1.14(1.08,1.21)$ & $1.79(1.05,2.53)$ \\
\hline Loitering with friends & $3.92(3.70,4.14)$ & $3.92(3.70,4.14)$ & $3.89(2.81,4.98)$ \\
\hline Go out secretly & $1.98(1.83,2.13)$ & $1.96(1.81,2.11)$ & $2.30(1.31,3.29)$ \\
\hline Illegal motorcycle activity & $1.42(1.31,1.54)$ & $1.42(1.31,1.54)$ & $1.41(0.86,1.95)$ \\
\hline Truancy & $1.53(1.42,1.65)$ & $1.51(1.39,1.62)$ & $2.05(1.25,2.86)$ \\
\hline
\end{tabular}

Table 3. Associated factors of alcohol drinking by simple and multiple logistic regression models

\begin{tabular}{|c|c|c|c|c|c|c|}
\hline \multirow{2}{*}{ Variable } & \multicolumn{3}{|c|}{ Simple Logistic Regression } & \multicolumn{3}{|c|}{ Multiple Logistic Regression } \\
\hline & b & Crude OR (95\% CI) & $\mathbf{p}$ & b & Adjusted OR (95\% CI) & $\mathbf{p}$ \\
\hline Age & -0.62 & $\begin{array}{c}0.53 \\
(0.38,0.76)\end{array}$ & 0.196 & -0.79 & $\begin{array}{c}0.46 \\
(0.31,0.67)\end{array}$ & $<0.001$ \\
\hline $\begin{array}{c}\text { Status of parents } \\
\text { Married } \\
\text { Divorced/ widowed/ } \\
\text { separated }\end{array}$ & $\begin{array}{c}1 \\
0.23\end{array}$ & $\begin{array}{c}0 \\
1.26 \\
(0.90,0.19)\end{array}$ & 0.180 & $\begin{array}{c}1 \\
1.47\end{array}$ & $\begin{array}{c}0 \\
4.35 \\
(1.25,15.19)\end{array}$ & 0.021 \\
\hline $\begin{array}{c}\text { Race } \\
\text { Malay } \\
\text { Other than Malay }\end{array}$ & $\begin{array}{c}1 \\
3.74\end{array}$ & $\begin{array}{c}0 \\
42.31 \\
(19.36,92.49) \\
\end{array}$ & $<0.001$ & $\begin{array}{c}1 \\
3.87\end{array}$ & $\begin{array}{c}0 \\
47.92 \\
(19.42,118.26) \\
\end{array}$ & 0.002 \\
\hline $\begin{array}{l}\text { Being around drunk } \\
\text { friends }\end{array}$ & 0.28 & $1.32(1.12,1.57)$ & 0.001 & 0.42 & $1.52(1.81,1.96)$ & 0.001 \\
\hline Peer problem & 0.301 & $\begin{array}{c}1.35 \\
(1.07,1.70)\end{array}$ & 0.010 & 0.332 & $1.39(1.01,1.93)$ & 0.046 \\
\hline
\end{tabular}

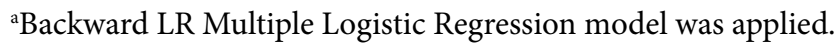

has strict alcohol trade rulings which may affect the accessibility towards alcoholic drinks. However, the reducing trend of state prevalence from $6.3 \%$ to $5.2 \%$ was a good sign and may reflect the success of public health prevention measures in the adolescent population. A review regarding measuring and preventing alcohol use amongst young people in Asia showed Malaysia had among the lower prevalence rates compared to other seven nations ${ }^{6}$. This shows that the socio-cultural and religious effect towards the consumption of alcohol is indeed prevalent.

Ever drinking of alcohol among Malay respondents in this study is about $1.5 \%$. This finding is similar with previous findings from the nationwide survey which showed that for ethnicity, Malays had the least prevalence while Chinese had the highest ${ }^{2,7}$. This may be attributed by differences in religious and cultural practices. The Chinese had the highest percentage of ever alcohol drinking, which was $55.4 \%$. It was not surprising that more than half of the Chinese respondents are ever drinkers as alcohol drinking is a part of the Chinese traditional and societal practice especially during festive season ${ }^{16}$.

The relatively younger mean age of ever alcohol drinkers and younger age as a significant risk factor for drinking is a worrying finding. A previous national study on adult alcohol drinkers showed the average age 
of alcohol drinking onset among the study population was 21 years old ${ }^{17}$. Other previous study had found that older age was associated with alcohol consumption ${ }^{18}$, ${ }^{19}$. This suggests that there may be some environmental factors that influence the current younger generation to try alcohol. Thus, the authorities should be more vigilant to prevent younger age adolescents from access to alcoholic drinks and prevention campaign should target the younger age group in order to prevent the trying of alcohol. The prevalence of ever drinking alcohol among female respondents was found to be slightly higher than males, which is in contrast to previous studies conducted in Malaysia ${ }^{5,18}$. However, gender was not shown to be significant in the final model. Studies in other countries showed that alcohol consumption was associated with being female and white ${ }^{19,20}$. This shows that the sociodemographic influence of alcohol consumption varies between countries as there are influences of the environment due differences in the culture, religion and government policies.

The significant associated factors in our final model for ever alcohol drinking among adolescents in this study are younger age, race other than Malay, having single parents, having family members taking alcohol, peer problems and having friends who have been drunk. Some other studies in Malaysia have shown current alcohol drinking to be more prevalent among Chinese and male adolescents, other than associated with substance use, experienced injury, engagement in sexual behaviors and fights ${ }^{6,16}$. Other studies have shown substance use, including alcohol was associated with delinquency and other high risk behaviours ${ }^{21}$. The association with other substance use, misconduct and risk behavior show the need of identifying this group of adolescents with consumption of alcohol as appropriate intervention can be done, not only for the prevention of the alcohol use disorders, but for other risk behaviours as well.

Results from this study also highlight the psychological influence underpinning trying of alcohol in adolescents. Peer problems, measured by SDQ were shown to be significantly associated with ever drinking. A previous study in Denmark also found that problems with friends to be associated with drinking alcohol in the past 30 days; but not problems with parents ${ }^{22}$. This is not surprising as adolescence is a phase where getting along with peers is important to ensure a good psychological well-being. Social acceptance was shown to be negatively associated with perception of rejection in adolescents ${ }^{23}$, which may be the initiating factor for consumption of alcohol. Thus, they may succumb to invitations to drink alcohol with friends to feel a sense of acceptance and to avoid the feeling of rejection. This condition would make it unfortunate for the adolescents who incidentally mingle with bad peers. Affiliation with delinquent peers was shown to be a risk factor for alcohol use in an American study ${ }^{20}$. This study noted that drinking alcohol by sixth grade was associated with externalizing behaviours such as sensation seeking, conduct problems and mingling with delinquent peers. Peer relationship also appeared to influence the health literacy of adolescents, where a positive peer attachment was associated with better health literacy ${ }^{24}$. This is important, as substance use prevention is a part of health literacy as it was included health promotion or disease prevention. Having peers who are very health vigilant and do not take substances due to health literacy influenced adolescents to have a good awareness of health themselves.

Independently, having been around drunken friends increased the odds of the adolescents to consume alcohol drinks. This is not surprising and was also shown in previous research ${ }^{6}$. However, a study in Denmark showed that being around friends who get drunk was associated with the respondent getting drunk, and was not significantly associated with any drinking in the past 30 days. This difference may be due to drinking alcohol being more common in the country; where the prevalence of adolescent drinking of almost $80 \%{ }^{20}$. A possible explanation of this is due to the need for a sense of belonging and trying to imitate habits shown by peers which are common aspects of adolescence ${ }^{25}$. It is due to these reasons that alcohol use and other substance abuse was associated with eating disorders and body image problems ${ }^{26}$. However, this association was not found in a local study ${ }^{27}$.

Another significant factor that contributes significantly to ever drinking of alcohol which is also related to psychology is family-related factors. Having divorced or widowed parents increase the odds of a respondent to consume alcoholic drinks. Status from divorced or widowed parents may affect respondents emotionally or indirectly increase the odds for trying alcoholic drinks by increasing the time spent with friends. Due to having single parent, there may be less family interaction and more family disturbances. Previous study did show that parents' interest in their children's free time activities and friends decreases risk behavior in adolescence, including alcohol consumption ${ }^{28}$. 
Another study had done in Europe showed which adolescent with strong family bond was less likely engaged in alcohol consumption ${ }^{18}$. A study in Brazil found that the factors related to family were skipping school without parental knowledge, parents not knowing what children do in their free time, having fewer meals with their parents, reporting that parents do not care or care little if they go home drunk, as well as having suffered domestic violence $^{19}$. Family dysfunction indeed influence the adolescents character as it was found that it contributed towards misconduct behavior of adolescents ${ }^{29}$. The adolescents who had any form of family dysfunction either structurally or psychologically had more tendency to have misconduct behaviours.

In this study, mean truancy score for those who ever drank alcohol was higher than those who never had any alcohol. It was then included in the multiple logistic regression analysis but was not shown to be statistically significant in the final model. A study in Brazil found that alcohol consumption was more in adolescents who skipped school without parental knowledge ${ }^{19}$. Another previous study also found that truant students were more likely to report alcohol consumption and alcohol related problems than non-truant students ${ }^{30}$. It may be due to environment in Terengganu with strong religious and cultural belief, making it unfavorable for them to get alcohol during school hour time.

The main limitation in the current study is the cross sectional design of the study, as it cannot be used to analyze behaviours over time. Future longitudinal study should be carried out which is more effective to determine the effect of intervening via peer problems towards alcohol intake. The sample used in this study was limited to school-going adolescents in Terengganu state only, which may affect generalizability. However, strengths of the study include the adequate sample size and a multivariate analysis. This study showed the significance of peers in alcohol consumption in adolescents. Future studies should use a longitudinal study design to test the screening and intervention via peer problems, using a national representative samples. Therefore, a more comprehensive prevention program for alcohol drinking could be proposed by using peer problem as a target screening and intervention.

\section{Conclusion}

Ever drinking of alcohol among adolescents was significantly associated with increased peer problem scores; together with other significantly associated factors; namely younger age, race other than Malay, had divorced or single parent and being around drunk friends. This study highlights the influence of peers in alcohol consumption in adolescents. Screening for peer problems may be a way to detect potential candidate for prevention of drinking. Future longitudinal study should be done to investigate the effects of intervening via reduction of peer problems among at-risk adolescents to prevent them from trying and being involved in alcohol drinking, thus reducing rate of alcohol addiction, morbidity and mortality in the future.

\section{Acknowledgement}

The authors are thankful to all participants who took part in this study. We wish to thank all schools and teachers who gave permission for their students to be involved in this study. We also are grateful to Universiti Sultan Zainal Abidin for funding the study (UNISZA/2017/SRGS/10).

\section{Conflict of Interest}

The authors declare no conflict of interest.

\section{References}

1. Shield K, Manthey J, Rylett M, Probst C, Wettlaufer A, Parry $\mathrm{CDH}$. National, regional, and global burdens of disease from 2000 to 2016 attributable to alcohol use: A comparative risk assessment study. Lancet Public Health. 2020; 5(1):E51-61. https://doi.org/10.1016/S2468-2667(19)30231-2

2. National Institute of Health. Fact sheet NHMS 2019. Malaysia; Ministry of Health [Internet]. 2020 [Cited 2020 May 31st]. Available from: http://iku.moh.gov.my/nhms2019.

3. NIDA. Principles of adolescent substance use disorder treatment: A research- based guide. National Institute on Drug Abuse [Internet]. 2020 [Cited 2020 Jan 17]. Available from: https://www.drugabuse.gov/publications/ principles-adolescent-substance-use-disorder-treatmentresearch-based-guide. 
4. Institute for Public Health (IPH). Adolescent Health Survey 2017, National Health and Morbidity Survey 2017. Malaysia; Ministry of Health [Internet]. 2017 [Cited 2020 Apr 30]. Available from: http://www.iku. gov.my/images/IKU/Document/REPORT/NHMS2017/ AHSReportNHMS2017.pdf. 2017.

5. Manickam MA, Mutalip MHA, Hamid HAA, Kamaruddin RB, Sabtu MY. Prevalence, comorbidities, and cofactors associated with alcohol consumption among school-going adolescents in Malaysia. Asia Pacific Journal of Public Health. 2014; 26(5):91S-9S. https://doi.org/10.1177/1010539514542194. PMid:25038196

6. Jiang $\mathrm{H}$, Xiang X, Hao W, Room R, Zhang X, Wang X. Measuring and preventing alcohol use and related harm among young people in Asian countries: a thematic review. Global Health Research and Policy. 2018; 3, 14. https:/doi.org/10.1186/ s41256-018-0070-2. PMid:29761160. PMCid:PMC5941657

7. Lim KH, Teh CH, Heng PP, Pan S, Ling MY, Yusoff MFM, et al. Source of cigarettes among youth smokers in Malaysia: Findings from the Tobacco and E-Cigarette survey among Malaysian school Adolescents (TECMA). Tobacco Induced Diseases. 2018; 16:51. https://doi.org/10.18332/tid/96297. PMid:31516448 PMCid:PMC6659477

8. WHO. Global School-based student Health Survey (GSHS). World Health Organization. [Internet]. 2020 [Cited 2020 Jan 18]. Available from: https://www.who.int/ ncds/surveillance/gshs/en/. 2020.

9. Goodman R, Ford T, Simmons H, Gatward R, Meltzer H. Using the Strengths and Difficulties Questionnaire (SDQ) to screen for child psychiatric disorders in a community sample. British Journal of Psychiatry. 2000; 177:534-9. https://doi.org/10.1192/bjp.177.6.534. PMid:11102329

10. Goodman R, Renfrew D, Mullick M. Predicting type of psychiatric disorder from Strengths and Difficulties Questionnaire (SDQ) scores in child mental health clinics in London and Dhaka. European Child and Adolescent Psychiatry. 2000; 9:129-34. https://doi.org/10.1007/ s007870050008. PMid:10926063

11. Björnsdotter A, Enebrink P, Ghaderi A. Psychometric properties of online administered parental Strengths and Difficulties Questionnaire (SDQ), and normative databased on combined online and paper-and-pencil administration. Child and Adolescent Psychiatry and Mental Health. 2013; 7(1): 40. https://doi.org/10.1186/1753-2000-7-40. PMid:24325882 PMCid:PMC3898053

12. Dickey WC, Blumberg S. Revisiting the factor structure of the Strengths and Difficulties Questionnaire: United States, 2001. Journal of the American Academy of Child \& Adolescent Psychiatry. 2004; 43:1159-67. https://doi. org/10.1097/01.chi.0000132808.36708.a9 PMid:15322420
13. Nurulhuda MH, Husain R, Aziz AA, Mazubir NN, Juhari $\mathrm{SN}$, Norwati D. Validation of the Malay version of the Self-rated Strength and Difficulties (SDQ) Questionnaire. International Journal of Academic Research in Business and Social Sciences. 2019; 9(11):358-73. https://doi. org/10.6007/IJARBSS/v9-i11/6553

14. Carlo G, Crockett LJ, Wilkinson JL, Beal SJ. The longitudinal relationships between rural adolescents' prosocial behaviors and young adult substance use. Youth and Adolescence. 2011; 40:1192. https://doi.org/10.1007/s10964-010-9588-4. PMid:20821257

15. Mi MF, Amer NA. Alcohol harm in Malaysia: Always the right time to discuss. Malaysian Journal of Psychiatry. 2014; 02(05).

16. Cheah KY. Socioeconomic determinants of alcohol consumption among non- malay's in Malaysia. Hitotsubashi Journal of Economics. 2015; 56:55-72

17. Hatta AMM, Rozanim K, Mala M, Akmal AHH, Riyanti S. Alcohol consumption and risky drinking patterns in Malaysia: Findings from NHMS 2011. Alcohol and Alcoholism. 2014; 49(5):593-9. https://doi.org/10.1093/alcalc/agu042. PMid:25015981

18. Bich TH, Nga PTQ, Quang LNQ, Van Minh H, Ng N, Juvekar $\mathrm{S}$, et al. Patterns of alcohol consumption in diverse rural adults populations in the Asian region. Glob Health Action. 2009; 2. https://doi.org/10.3402/gha.v2i0.2017. PMid:20027253 PMCid:PMC2785538

19. Malta DC, Mascarenhas MD, Porto DL, Barreto SM, Morais Neto OL. Exposição ao álcool entre escolares e fatores associados [Exposure to alcohol among adolescent students and associated factors]. Rev Saude Publica. 2014; 48(1):5262. https://doi.org/10.1590/S0034-8910.2014048004563. PMid:24789637. PMCid:PMC4206131

20. Isaksson J, Sjöblom S, Schwab-Stone M, Stickley A, Ruchkin V. Risk factors associated with alcohol use in early adolescence among american inner-city youth: A longitudinal study, substance use \& misuse. 2020; 55:3, 358-66. https://doi.org/10.1080/10826084.2019.1671867. PMid:31686574

21. Mohamad M, Mohammad M, Mat Ali NA, Awang Z. The impact of life satisfaction on substance abuse: Delinquency as a mediator. International Journal of Adolescence and Youth. 2018; 23(1):25-35. https://doi.org/10.1080/026738 43.2016.1267021

22. König C, Skriver MV, Iburg KM, Rowlands G. Understanding educational and psychosocial factors associated with alcohol use among adolescents in Denmark; Implications for health literacy interventions. International Journal of Environmental Research and Public Health. 2018; 15(8):1671. https://doi.org/10.3390/ijerph15081671. PMid:30082674 PMCid:PMC6121249 
23. Badaly D, Schwartz D, Gorman AH. Social status, perceived social reputations, and perceived dyadic relationships in early adolescence. Social Development. 2012; 21:482-500. https://doi.org/10.1111/j.1467-9507.2011.00646.

24. Hamzah SR, Ismail M, Nor ZM. Does attachment to parents and peers influence health literacy among adolescents in Malaysia? Kontakt. 2018; 20(4):e348-355. https://doi.org/10.1016/j.kontakt.2018.10.006

25. Granville-Garcia AF, Clementino MA, Gomes MdC, Firmino RT, Ribeiro GLA, Siqueira MBLD. Alcohol consumption among adolescents: Ciência \& Saúde Coletiva. 2014; 19(01):7-16. https://doi.org/10.1590/141381232014191.1989. PMid:24473598

26. Von Ranson KM, Iacono WG, McGue M. Disordered eating and substance use in an epidemiological sample: I. Associations within individuals. International Journal of Eating Disorders. 2002; 31(4):389-403. https://doi. org/10.1002/eat.10050. PMid:11948644

27. Mazubir NN, Hassan NM, Aziz AA, Suan WB. Disordered eating behaviour among school-going adolescents: prevalence and associated factors. International Journal of Academic Research in Progressive Education and Development. 2020; 9(1):193-207.

28. Malta DC, Mascarenhas MD, Porto DL, Barreto SM, Morais Neto OL. Exposição ao álcool entre escolares e fatores associados [Exposure to alcohol among adolescent students and associated factors]. Rev Saude Publica. 2014; 48(1):5262. https://doi.org/10.1590/S0034-8910.2014048004563. PMid:24789637 PMCid:PMC4206131

29. Sham FM, Nazim AM, Mastor KA, Radzi AM. Religiosity as mediator in reducing misconduct of adolescents-atrisk. Journal of Religion and Health. 2019 Nov. https://doi. org/10.1007/s10943-019-00951-2. PMid:31732845

30. Htet H, Saw YM, Saw TN, Htun NMM, Lay Mon K, Cho $\mathrm{SM}$, et al. Prevalence of alcohol consumption and its risk factors among university students: A cross-sectional study across six universities in Myanmar. PLoS ONE. 2020; 15(2). https://doi.org/10.1371/journal.pone.0229329. PMid:32084226. PMCid:PMC7034886 